\title{
What coatis and mongooses have in common?
}

\author{
Ivan Sazima ${ }^{1,2,3}$ \\ ${ }^{1}$ Museu de Zoologia, Universidade Estadual de Campinas - UNICAMP, \\ Rua Albert Einstein, s/n, CP 6109, CEP 13083-970, Campinas, SP, Brasil, www.unicamp.br \\ ${ }^{2}$ Retired and associated as voluntary researcher \\ ${ }^{3}$ Corresponding author: Ivan Sazima, e-mail: isazima@gmail.com
}

SAZIMA, I. What coatis and mongooses have in common? Biota Neptrop. 10(3): http://www.biotaneotropica. org.br/v10n3/en/abstract?short-communication+bn02410032010.

\begin{abstract}
The coatis (Procyonidae) and some species of mongooses (Herpestidae) are diurnal, small to mediumsized carnivores that live in groups and feed opportunistically on small animals and fruits. A comparison of selected features is here presented for two coati species (Nasua narica and N. nasua) and the banded mongoose (Mungos mungo). The former two dwell in the Neotropical region, whereas the latter occurs in the Ethiopian realm. Both the coatis and the mongoose are apt to live near human settlements and capitalise on food refuse. Additionally, coatis and mongooses habituate to humans, and sometimes are a nuisance. These habits, plus their almost constant quest for food, lead these carnivores to meet other mammal types at feeders and garbage dumps and associate with these animals. White-nosed coatis associate with the Baird's tapir (Tapirus bairdii) and pick ticks on its body, whereas the banded mongoose does so with the common warthog (Phacochoerus africanus). These seem to be the two sole recorded instances of mammals cleaning non-conspecific mammals, and illustrate a remarkable case of convergence.
\end{abstract}

Keywords: opportunistic behaviour, cleaning symbiosis, convergence, Procyonidae, Herpestidae.

SAZIMA, I. O que quatis e mangustos têm em comum? Biota Neptrop. 10(3): http://www.biotaneotropica. org.br/v10n3/pt/abstract?short-communication+bn02410032010.

Resumo: Os quatis (Procyonidae) e algumas espécies de mangustos (Herpestidae) são carnívoros diurnos de pequeno a médio porte, que vivem em grupos e se alimentam oportunisticamente de pequenos animais e frutos. Uma comparação de algumas características é aqui apresentada para duas espécies de quatis (Nasua narica e N. nasua) e o mangusto-listrado (Mungos mungo). Os dois primeiros habitam a região Neotropical, ao passo que o mangusto vive na região Etíope. Tanto os quatis como o mangusto são capazes de viver próximos de povoados e aproveitam restos de alimento. Ademais, quatis e mangustos se habituam a humanos e por vezes constituem um estorvo. Esses hábitos, mais a sua quase constante procura por alimento, levam estes carnívoros a encontrar outros tipos de mamíferos em comedouros e lixeiras, e a se associarem a estes animais. O quati-de-nariz-branco (N. narica) associa-se à anta-de-baird (Tapirus bairdii) e cata carrapatos no corpo deste herbívoro, ao passo que o mangusto faz o mesmo com o facóquero ou javali-africano (Phacochoerus africanus). Estes parecem ser os dois únicos registros de mamíferos limpando mamíferos de espécies outras que a própria, e ilustram um caso notável de convergência.

Palavras-chave: comportamento oportunista, simbiose de limpeza, convergência, Procyonidae, Herpestidae. 


\section{Introduction}

Cleaning symbiosis is an interspecific association in which an animal (the cleaner) seeks food on the body surface of other animals (the clients) which, in turn, become free of ectoparasites and debris. This association is best documented among reef fishes (reviews in Losey 1987, Côté 2000, Grutter 2005). There are several examples of cleaners among birds as well (e.g. Dean \& MacDonald 1981, Ruggiero \& Ewes 1988, Sazima 2007), the most acknowledged association being that of oxpeckers - two species of tick-removing and sore-pecking buphagid birds (genus Buphagus) - and ungulate mammals in Africa (Craig 2009). However, instances of cleaners among mammals are strikingly few and so far involve two species of carnivores, a procyonid and a herpestid (Overall 1980, McClearn 1992, Cant 2008, Gilchrist et al. 2009).

The purpose of this paper is to present and compare selected morphological, ecological, and behavioural features of two coati species (Nasua narica and N. nasua) and the banded mongoose (Mungos mungo). The coatis dwell in the Neotropical region, whereas the mongoose occurs in the Ethiopian realm (Gilchrist et al. 2009, Kay 2009). The comparison reveals that the coatis and the banded mongoose share several characteristics, which may account for the fact that the white-nosed coati ( N. narica) and the banded mongoose (Mungos mungo) are the only mammals recorded to pick ticks from medium-sized to large ungulates. I comment on this type of cleaning symbiosis, which remains elusive and poorly known, and make a renewed plea for more studies on natural history of organisms.

\section{Material and Methods}

Data on the South American coati (Nasua nasua) were obtained in the field at the Pantanal area near Poconé ( 16 $6^{\circ} 26^{\prime} \mathrm{S}$ and $56^{\circ} 39^{\prime} \mathrm{W}$ ) in South-Western Brazil, and at the Itatiaia National Park near Itatiaia $\left(\sim 22^{\circ} 26^{\prime} \mathrm{S}\right.$ and $\left.44^{\circ} 36^{\prime} \mathrm{W}\right)$ in South-Eastern Brazil. For the white-nosed coati ( $N$. narica) and the banded mongoose (Mungos mungo), data were gathered from literature and brief interviews with professional biologists, amateur naturalists and photographers who recorded the behaviour of coatis or mongooses in nature, associated or not with other mammals. Photographs were further used to describe and illustrate the behaviour of the coatis and the mongooses; voucher copies (when copyright allowed) are on file at the Museu de Zoologia da Universidade Estadual de Campinas (ZUEC). Analyses of the relative occurrence of cleaning behaviour here described were not attempted, due to lack of suitable data in the literature (Overall 1980, McClearn 1992, Cant 2008, Gilchrist et al. 2009).

\section{Results and Discussion}

The white-nosed coati, Nasua narica (L.) and the South American coati, Nasua nasua (L.) are members of the Procyonidae, carnivores from the New World, whereas the banded mongoose, Mungos mungo (Gmelin) is a member of the Herpestidae, carnivores from the Old World (Kay 2009, Gilchrist et al. 2009). Coatis are medium-sized (body length 42-68 cm, mass $2.7-7.2 \mathrm{~kg}$ ), whereas the banded mongoose is relatively small for a carnivore (body length $30-40 \mathrm{~cm}$, mass $0.89-1.88 \mathrm{~kg}$ ); males are larger than females in both the coatis and the mongoose (Emmons 1990, Kay 2009, Gilchrist et al. 2009).

Both species of coatis are found mostly in a variety of forested areas, although they dwell in open areas as well (Kay 2009, IS pers. obs.), whereas the banded mongoose dwells in savannah and woodland areas (Gilchrist et al. 2009). Coatis are omnivores that forage on arthropods, fruits and small vertebrates (Emmons 1990, Kay 2009 , IS pers. obs.), whereas the mongoose is essentially insectivorous
(Gilchrist et al. 2009, Cant \& Gilchrist 2010). The coatis are good climbers that forage on trees, and act as fruit dispersers (Alves-Costa \& Eterovick 2007, Kay 2009), whereas the mongoose climb trees mostly under stress, and fruits are of much lesser importance in its diet (Gilchrist et al. 2009). The coatis and the mongoose are opportunistic foragers that search for terrestrial preys sniffing, and scraping the ground with their forepaws (Figure 1). Both these carnivore types are diurnal, travelling and foraging in bands (Figure 2). Coati groups are composed mostly of adult females and their offspring, whereas banded mongoose groups contain adult males, females, and their young (Emmons 1990, Kay 2009, Gilchrist et al. 2009). Female coatis are social groomers that remove ectoparasites from other group members (Kaufman 1962, Bisbal 1986), and the banded mongooses also groom each other and remove ectoparasites; additionally, this allogrooming maintains bonds between group members (Kay 2009, Gilchrist et al. 2009).

The two coati species and the banded mongoose habituate to human settlements (Figure 3), perhaps due to their investigative nature and living in bands. The former characteristic is advantageous for foraging opportunities, whereas the latter one provides a more effective defence (Kay 2009, Gilchrist et al. 2009, Cant \& Gilchrist 2010). The coatis and the mongoose take advantage of human waste at garbage dumps and are adept to beg for food (Figure 4) at sites where they are tolerated or at least not chased or otherwise harassed (Overall 1980, McClearn 1992, Cant 2008). Indeed, at some sites coatis may be a nuisance due to their scurrying around, entering dustbins, begging
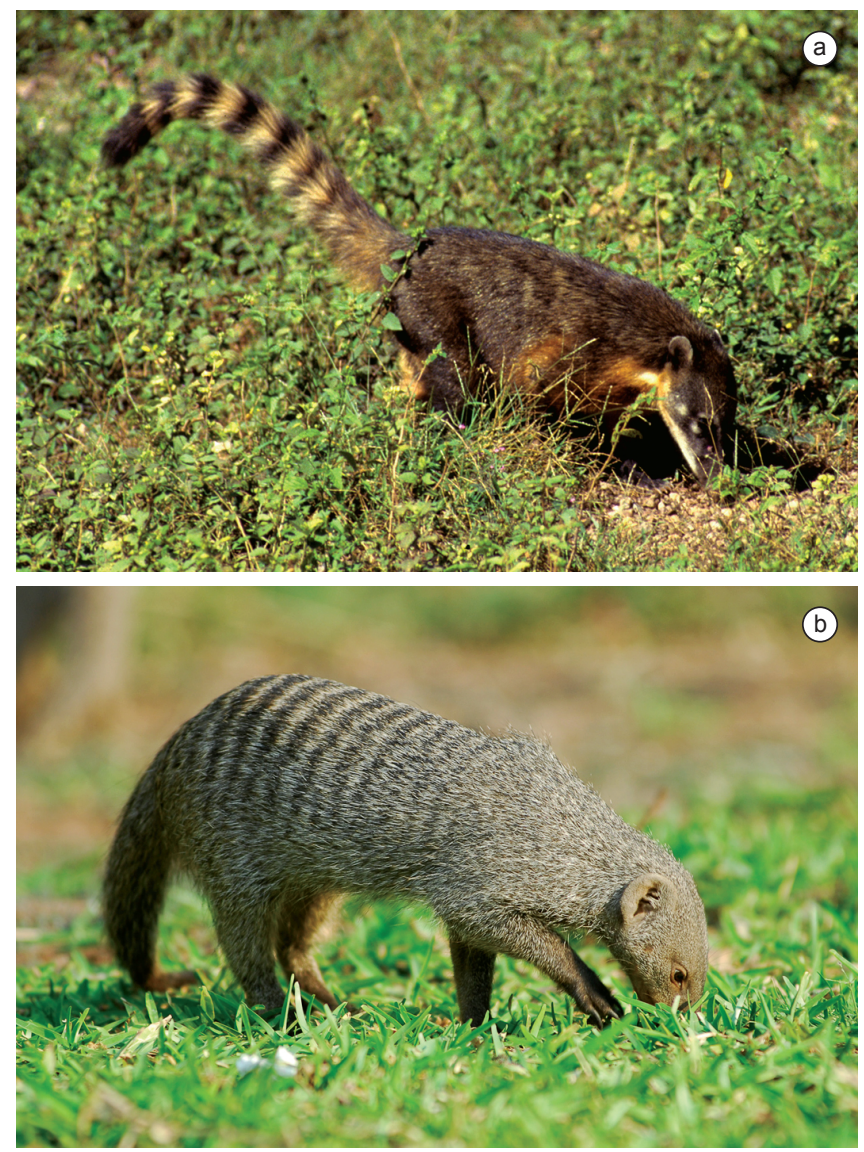

Figure 1. Foraging on the ground, a South American coati (Nasua nasua) (a) and a banded mongoose (Mungos mungo) (b) sniff and scrape the substratum searching for prey. Photo credits: Ivan Sazima (a); Jean-Louis Vandevivère (b). 

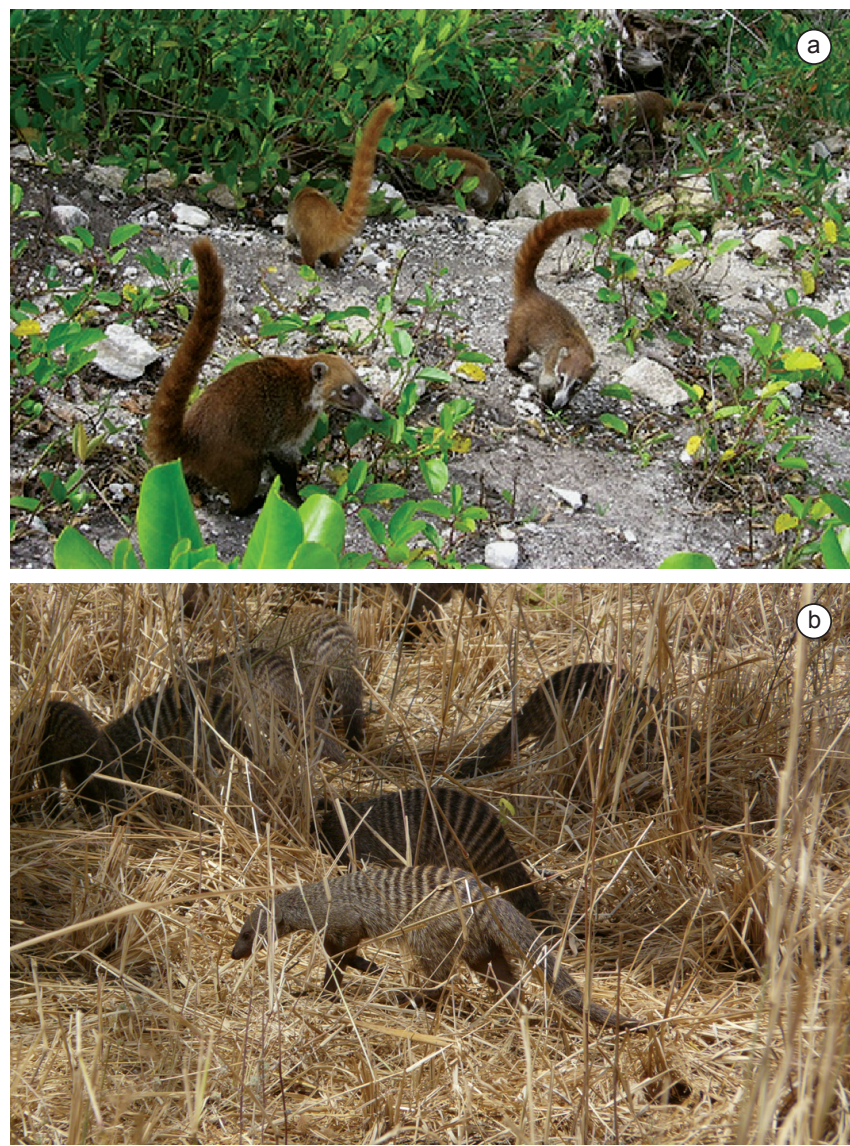

Figure 2. Coatis - here the white-nosed coati (Nasua narica) (a), and the banded mongoose (Mungos mungo) (b) travel and forage in bands. Photo credits: Iwona Erskine-Kellie (a); Dov Murik (b).

for food, and even stealing handheld candies (C. Sazima pers. comm., IS pers. obs.), and the same applies to the banded mongoose (M. A. Cant, pers. comm.). However, tourists mostly regard both the coatis and mongooses as inquisitive and lovable animals (I. Clemens pers. comm., G. Gerson Lohman-Braun pers. comm., IS pers. obs.).

The tendency of some groups of coatis and mongooses to dwell near human settlements and to seek food in garbage dumps bring these carnivores in contact with other, waste-feeding vertebrates such as birds and mammals. At the Queen Elizabeth National Park in Uganda, East Africa, the banded mongoose meets common warthogs, Phacochoerus africanus (Gmelin) at garbage dumps and other sites with food provided by humans (Cant 2008, Gilchrist et al. 2009), whereas on Barro Colorado Island, Panama, Central America, the white-nosed coati met the Baird's tapir, Tapirus bairdii (Gill) at a field station at which supplementary food was provided (Overall 1980, McClearn 1992).

The meeting between coatis and tapirs provides an opportunity for the former to obtain additional and nutritive food, picking ticks on the latter (Figure 5a), and a similar opportunity comes about with mongooses and warthogs (Figure 5b). Usually a coati approached a standing tapir and rested one or the two forepaws against the tapir's front legs, after which the tapir sank to the ground and lay on its side allowing the carnivore to groom it and pick blood-engorged ticks on its body (McClearn 1992). On the other hand, mongooses usually approach resting warthogs and groom and pick ticks on the body of these ungulates; on occasions, a warthog would knee or lay on its side, 'inviting' the mongooses and even allowing them to pick
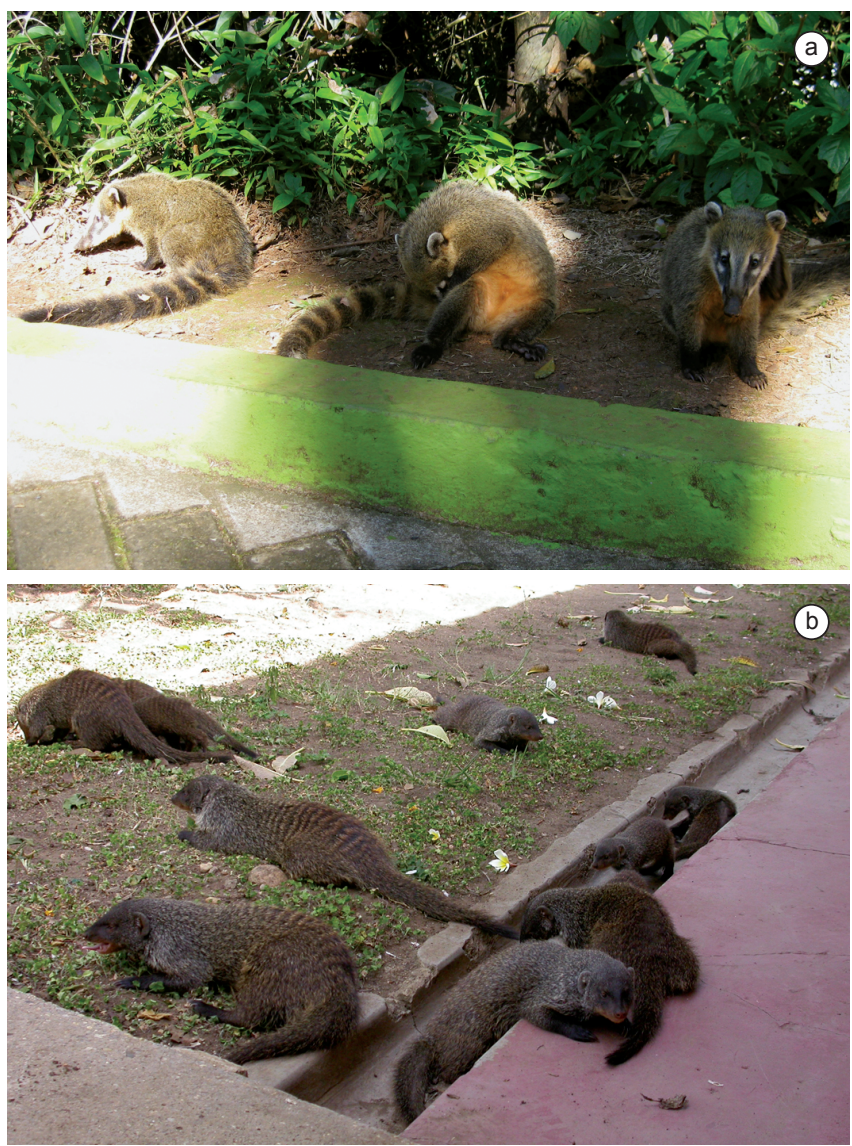

Figure 3. Where not chased or otherwise harassed, coatis - here Nasua nasua (a) and the banded mongoose (Mungos mungo) (b) habituate to humans and their settlements. Photo credits: Cristina Sazima (a); Duncan Wright (b).

ticks from its under parts (ARKive 2010, A. Shah pers. comm.). The shared inquisitive, opportunistic foraging in groups and social grooming of the coatis and the banded mongooses eventually led both these mammal types to groom medium-sized to large ungulates and pick ticks from them. These seem to be the two sole recorded instances of mammals grooming, and picking ectoparasites from, non-conspecific mammals in nature and illustrate a remarkable case of convergence.

The South American tapir, Tapirus terrestris (L.) is cleaned by birds such as the black caracara, Daptrius ater Vieillot and the yellowheaded caracara, Milvago chimachima (Vieillot) and poses for them lying on its side and exposing its under parts (Peres 1996, IS pers. obs.). Baird's tapir is likely cleaned by the yellow-headed caracara as well, since the distribution of this falcon and the tapir overlaps in some areas of Central America (Emmons 1990, Ferguson-Lees \& Christie 2005). Thus, tick-picking by coatis may be managed by a tapir in a similar way it handles birds, i.e., letting the mammals to pick ticks on its body, and posing and lying on its side to facilitate the access to its under parts. On the other hand, warthogs are usually cleaned by oxpeckers such as Buphagus erythrorhynchus Stanley, but are not known to pose for them (P. van Schalkwyk pers. comm.), perhaps due to the sore-pecking and blood-drinking habit of these birds (Craig 2009). However, a warthog may kneel to initiate a cleaning session, or pose for banded mongooses lying on its side (ARKive 2010, A. Shah pers. comm.). Thus, tick-picking by mongooses may be managed by this medium-sized ungulate in a slightly different way it handles birds, i.e., letting the mammals to forage on its body and sometimes even 

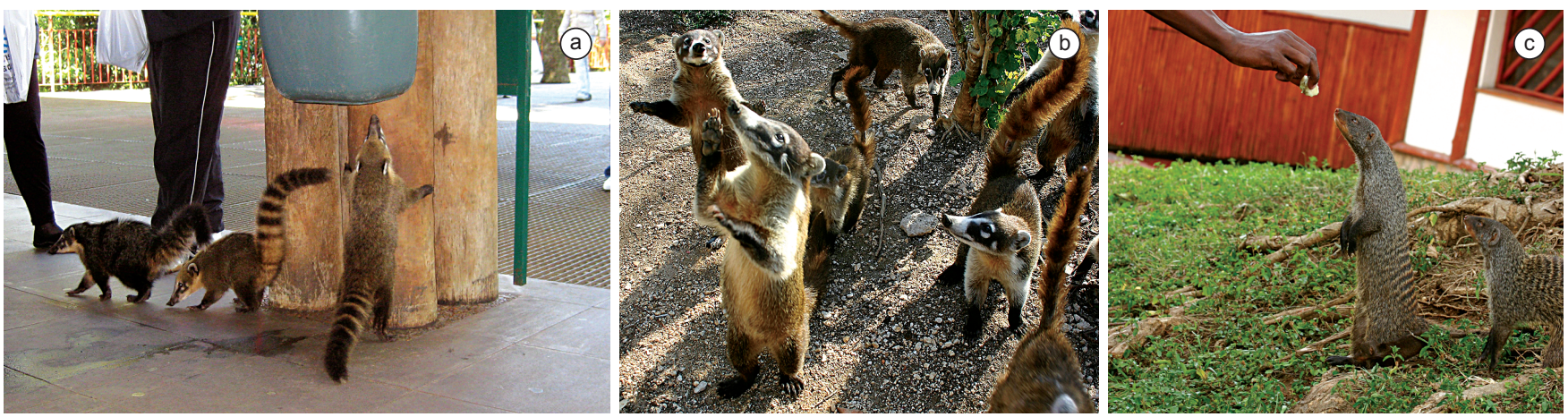

Figure 4. Coatis - here Nasua nasua (a) and Nasua narica (b), and the banded mongoose (Mungos mungo) (c) take advantage of human waste and are adept to beg for food. Photo credits: Cristina Sazima (a); Inga Clemens (b); Gisela Gerson Lohman-Braun (c).
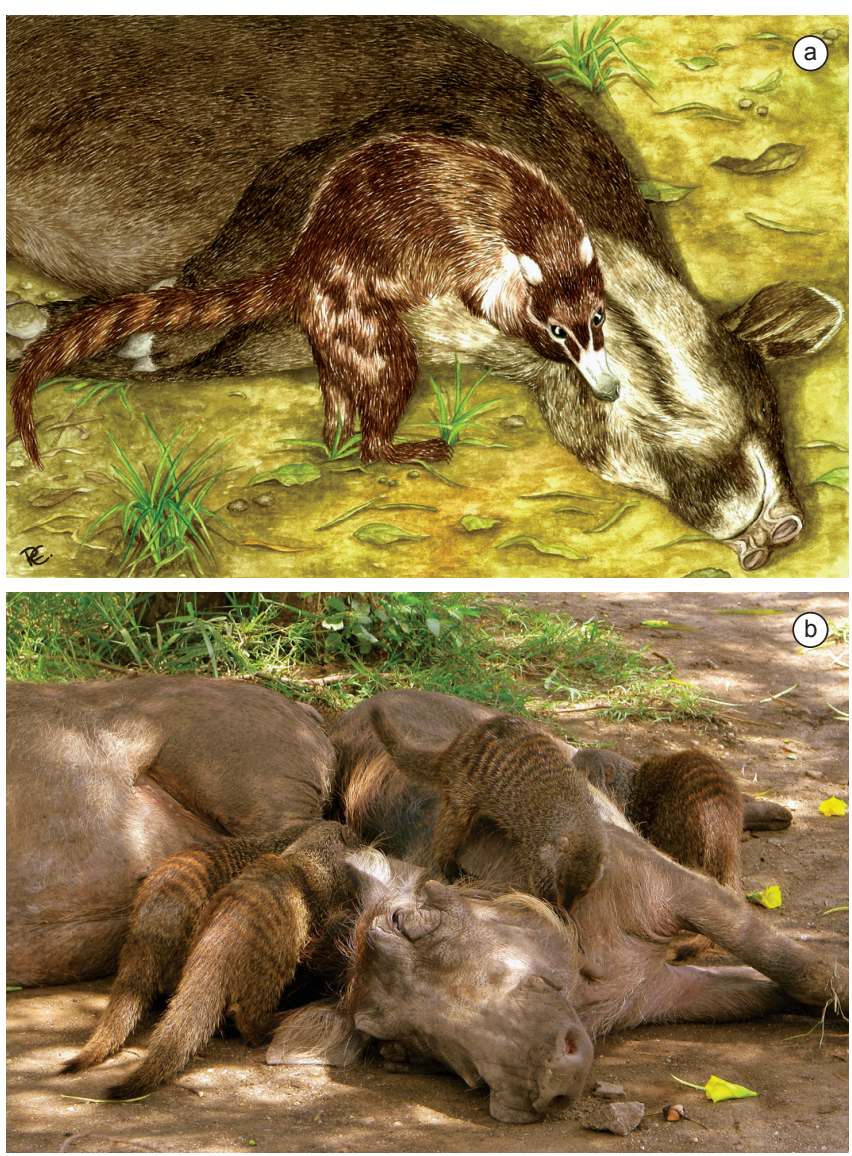

Figure 5. Both the white-nosed coati Nasua narica (a) and the banded mongoose (Mungos mungo) (b) pick ticks from ungulates. The coati grooms a Baird's tapir (Tapirus bairdii), whereas the mongoose grooms the common warthog (Phacochoerus africanus). Watercolour by Paula Eterovick (a) inspired on a photo by Deedra McClearn. Photo credit: Arturo Solano (b).

initiating the cleaning session and/or facilitating access to its under parts. These differences may be due to the oxpeckers' sore-pecking habit, as opposed to the mongooses' tick-picking only.

Lying on the side and exposing the under parts is an 'inviting' posture reported for capybaras, Hydrochoerus hydrochaeris (L.) and wild boar, Sus scrofa L. during cleaning interactions with birds (Massei \& Genov 1995, Sazima \& Sazima 2010), warthogs cleaned by mongooses (see above), and tapirs cleaned by birds and coatis (Overall 1980, McClearn 1992, Peres 1996). This inviting posture of ungulate and rodent hosts during cleaning associations with birds is briefly commented upon by Sazima \& Sazima (2010).

So far, tick-picking by banded mongooses (Mungos mungo) on warthogs (Phacochoerus africanus) is recorded at the Queen Elizabeth National Park in Uganda and Masai Mara in Kenya (Cant 2008, Gilchrist et al. 2009), mostly near garbage dumps and supplementary feeding sites provided by humans. The extent to which this association occurs in the wild, i.e., far from human influence, is unknown (M. A. Cant, pers. comm.). A similar association between white-nosed coatis (Nasua narica) and Baird's tapirs (Tapirus bairdii) was recorded for a given period on Barro Colorado Island, Panama, but is no longer observed there once the supplementary feeding by humans ended (Overall 1980, McClearn 1992). However, given the behaviour that both the coatis and the tapirs displayed when they met at human settlements, it may well continue in the wild (McClearn 1992). Additionally, there is a possibility that the tickpicking association may occur between the South American coati (Nasua nasua) and the Brazilian tapir (Tapirus terrestris) under favourable circumstances, given their overall behavioural similarity to their two Central American counterparts. Indeed, I observed two pet South American coatis grooming a large dog and picking ticks from its body. However, to what extent this association could be expected to occur in the wild is a question yet to be answered (see McClearn 1992 for Tapirus bairdii). As noted above, tapirs and warthogs are cleaned by birds in the wild (Peres 1996, Craig 2009, P. van Schalkwyk pers. comm.), a factor that plausibly increases their propensity to associate with mammals such as coatis and mongooses to be rid of ectoparasites. Thus, it can be said that tapirs and warthogs also present a degree of convergence, at least from the cleaning association perspective.

Our knowledge of terrestrial cleaning associations in the Neotropics remains poorly known (e.g. McClearn 1992, Peres 1996, Sazima 2007, Sazima \& Sazima 2010), and additional studies are needed to change this situation. Wildlife-oriented tourists, amateur naturalists, and amateur and professional wildlife photographers and filmmakers may help to bring this and other vertebrate associations to the attention of professional biologists, and their efforts should always be encouraged (see Sazima \& Sazima 2010 for this view). There are several species and behaviours that remain scientifically unrecorded but are available to the general public through illustrated books on animals and wildlife documentaries. Thus, I make renewed plea to professional biologists for more studies on the supposedly outdated descriptive natural history of organisms, for the purpose of knowing and understanding better their life, how they interact with their environment, and how they might have evolved (see Greene 2005 for a candid and convincing discussion of some reasons to do such studies). 


\section{Acknowledgements}

I am grateful to Inga Clemens, Iwona Erskine-Kellie, Gisela Gerson Lohman-Braun, Cristina Sazima, Philippe Boissel, Michael Cant, Claus and Sharon Ellef, Dov Murik, Peet van Schalkwyk, Anup Shah, Arturo Solano, Jean-Louis Vandevivère, Duncan Wright, and Patrick Young for their essential photographs (even if I was unable to use all of them) and for generously sharing with me their records and observations on coatis, banded mongooses, and warthogs; Paula Eterovick for her graceful watercolour; Cristina Sazima for her thoughtful review; Marlies Sazima for her loving support and company in the field. Two anonymous referees and the area editor improved the manuscript.

\section{References}

ALVES-COSTA, C.P. \& ETEROVICK, P.C. 2007. Seed dispersal services by coatis (Nasua nasua, Procyonidae) and their redundancy with other frugivores in southeastern Brazil. Acta Oecol. 32(1):77-92.

ARKive. 2010. Banded mongooses grooming common warthog. http://www. arkive.org/common-warthog/phacochoerus-africanus/video-11a.html (last access on 24/04/2010).

BISBAL, E.F.J. 1986. Food habits of some Neotropical carnivores in Venezuela. Mammalia 50(3):329-340.

CANT, M. \& GILCHRIST, J.S. 2010. Species profile. Banded mongoose, Mungos mungo (Gmelin). http://bandedmongoose.org/ (last access on 24/04/2010)

CANT, M. 2008. Make way for team mongoose. BBC Wildlife 8:44-49.

CÔTÉ, I.M. 2000. Evolution and ecology of cleaning symbiosis in the sea. Ocean. Mar. Biol. Ann. Rev. 38:311-355.

CRAIG, A.J.F.K. 2009. Family Buphagidae (oxpeckers). In Handbook of the birds of the world, vol. 14 Bush-shrikes to Old World sparrows (J. del Hoyo, A. Elliot \& D.A. Christie, eds.). Lynx Editions, Barcelona, p. 642-653.

DEAN, W.R.J. \& MacDONALD, I.A.W. 1981. A review of African birds feeding in association with mammals. Ostrich 52:135-155.

EMMONS, L.H. 1990. Neotropical rainforest mammals: a field guide. University of Chicago Press, Chicago, 281p.

FERGUSON-LEES, j. \& CHRISTIE, D.A. 2005. Raptors of the world. Princeton University Press, Princeton, 320p.
GILCHRIST, J.S., JENNINGS, A.P., VERON, G. \& CAVALLINI, P. 2009. Family Herpestidae (mongooses). In Handbook of the mammals of the world, vol.1 Carnivores (D.E. Wilson \& R.A. Mittermeier, eds.). Lynx Editions, Barcelona, p. 262-328.

GREENE, H.W. 2005. Organisms in nature as a central focus for biology. Trends Ecol. Evol. 20(1):23-27.

GRUTTER, A.S. 2005. Cleaning mutualism in the sea. In Marine parasitology (K. Rohde, ed.). CSIRO Publishing, Collingwood, p. 264-278.

KAUFMANN, J.H. 1962. Ecology and social behaviour of the coati, Nasua narica on Barro Colorado Island, Panama. Univ. Calif. Publ. Zool. 60(3):95-222.

KAY, R. 2009. Family Procyonidae (racoons). In Handbook of mammals of the world, Vol.1 Carnivores (D.E. Wilson \& R.A. Mittermeier, eds.). Lynx Editions, Barcelona, p. 504-530.

LOSEY, G.S. 1987. Cleaning symbiosis. Symbiosis 4(1):229-258.

MASSEI, G. \& GENOW, P.V. 1995. Observations of black-billed magpie (Pica pica) and carrion crow (Corvus corone cornix) grooming wild boars (Sus scrofa). J. Zool. 236(2):338-341.

McCLEARN, D. 1992. The rise and fall of a mutualism? Coatis, tapirs, and ticks on Barro Colorado Island, Panamá. Biotropica 24(2a):220-222.

OVERALL, K.L. 1980. Coatis, tapirs, and ticks: a case of mammalian interspecific grooming. Biotropica 12(2):158.

PERES, C.A. 1996. Ungulate ectoparasite removal by Black Caracaras and Pale-winged Trumpeters in Amazonian forests. Wilson Bull. 108(1):170-175.

RUGGIERO, R.G. \& EVES, H.E. 1988. Bird-mammal associations in forest openings of northern Congo (Brazzaville). Afr. J. Ecol. 36:183-193.

SAZIMA, I. 2007. Unexpected cleaners: Black Vultures (Coragyps atratus) remove debris, ticks, and peck at sores of capybaras (Hydrochoerus hydrochaeris), with an overview of tick-removing birds in Brazil. Rev. Bras. Ornitol. 15(3):417-426.

SAZIMA, I. \& SAZIMA, C. 2010. Cleaner birds in Brazil: update and brief reappraisal. Biota Neotrop. 10(1):327-331 http://www.biotaneotropica org.br/v10n1/pt/abstract?article+bn00710012010

Received 13/05/2010

Revised 18/07/2010

Accepted 02/08/2010 